\title{
Prediction of Software-Based Sentence-in-Noise Recognition Thresholds of Hearing-Impaired Listeners
}

\author{
Gwang Min Kim ${ }^{1,2}$, Jae Hee Lee ${ }^{1,3}$ \\ 'Department of Audiology and Speech-Language Pathology, Hallym University of Graduate Studies, Seoul, Korea \\ ${ }^{2}$ Oticon Hearing Care Jong-ro Center, Seoul, Korea \\ ${ }^{3}$ HUGS Center for Hearing and Speech Research, Seoul, Korea
}

Received: March 10, 2020

Revised: March 26, 2020

Accepted: April 1, 2020

\section{Correspondence:}

Jae Hee Lee, PhD

Department of Audiology and Speech-Language Pathology,

HUGS Center for Hearing and

Speech Research,

Hallym University of Graduate Studies, 427 Yeoksam-ro, Gangnam-gu,

Seoul 06197, Korea

Tel: +82-2-2051-4952

Fax: +82-2-3451-6618

E-mail: leejaehee@hallym.ac.kr
Purpose: Although hearing-impaired (HI) listeners often have difficulty understanding in noise as their primary complaints, the speech-in-noise intelligibility test is not conducted as a standard audiologic test battery. This study investigated whether the speech audiometry in quiet accurately reflects the sentence-in-noise intelligibility of HI listeners. Methods: Sixty-two HI listeners participated. All the $\mathrm{HI}$ listeners had symmetrical high-frequency hearing loss and bilaterally worn hearing aids. Twenty-five normal-hearing $(\mathrm{NH})$ listeners also participated as a control group. The unaided word and sentence recognition scores (WRS and SRS) were obtained in quiet at individually determined most comfortable loudness level. With bilateral hearing aids, the aided WRS and SRS were evaluated at a normal conversational level. The software-based Korean Matrix sentence in noise test was administered at a fixed level (65 dB SPL) of noise while adjusting the sentence level adaptively based on the listener's response. The signal-to-noise ratio (SNR) required to achieve $50 \%$ intelligibility (speech recognition thresholds, SRTs) was obtained. Results: On average, the aided SRT of HI listeners was 0.1 dB SNR, and the mean SRT of NH adults was -8.91 dB SNR. The Matrix sentence-in-noise intelligibility was not sufficiently explained by the unaided WRS or unaided SRS. Conclusion: A traditional measure of the unaided speech-in-quiet recognition cannot accurately predict the aided speech-innoise intelligibility. Clinically, a software-based sentence-in-noise intelligibility test is recommended to directly confirm the actual benefits of hearing aid in noisy situations.

Key Words: Matrix sentence test, Software-based sentence-in-noise recognition, Speech-in-noise intelligibility.

\section{INTRODUCTION}

어음청각검사(speech audiometry)는 대상자의 일상생활 속 의사소통능력을 평가 및 예측하는 청각검사로 1940년대 이후 순음청력검사와 더불어 기초 청각검사 중 하나로 시행되어 왔 다(Mendel, 2008; Wilson, 2011). 어음청각검사에서는 단음절 혹은 문장을 자극 신호로 제시하며 대상자가 옳게 인지한 단어 혹은 문장을 통해 단어인지도(word recognition score, WRS), 문장인지도(sentence recognition score, SRS) 등을 측정한다. 어음청각검사 시 사용하는 어음 목록은 목록 간 음소 균형, 음 향학적 특성, 단어의 사용 빈도 및 어휘적 요소 등을 고려하여 구성하며, 신뢰도와 타당도 검증, 표준화 작업을 완료하여야 도

(c) This is an Open Access article distributed under the terms of the Creative Commons Attribution Non-Commercial License (https://creativecommons.org/licenses/by-nc/4.0) which permits unrestricted non-commercial use, distribution, and reproduction in any medium, provided the original work is properly cited.
구로서 사용할 수 있다(Mendel \& Danhauer, 1997). 그러나 국 내의 경우 음향학적 분석 및 신뢰도, 타당도 검증 등을 하지 않 은 단음절 목록을 임상에서 사용하는 문제점이 보고된 바 있다 (Byun et al., 2005). 이를 고려하여 조용한 상황에서 이음절, 단 음절, 문장을 이용하여 인지역치 혹은 인지도를 신뢰도 있게 측 정 가능한 한국어 어음청각검사 도구가 개발되었으며(Lee et al., 2010), 학령 전기 혹은 학령기 아동, 성인을 대상으로 녹음 된 음원을 통해 어음청각검사가 가능하다는 장점을 가진다.

난청인은 보장구 착용에도 불구하고 소음 상황에서 의사소 통 시 어려움을 보이며, 이러한 소음 상황에서의 어려움은 보청 기 부적응 혹은 만족도 저하와 연결될 수 있다(McCormack \& Fortnum, 2013). 보장구 착용 전 난청인의 의사소통능력이 어 떠한지, 보청기 착용 후 얼마나 개선되는지 정량화하기 위해 조 용한 상황보다는 소음 상황에서 어음인지를 평가하는 것이 더 적절하다(Taylor, 2003; Wilson, 2011). 따라서 대상자의 일상 
생활 속 의사소통능력을 정량화하기 위해 Hearing in noise test (HINT) (Nilsson et al., 1994), Quick speech-in-noise test (Killion et al., 2004), Matrix test (Akeroyd et al., 2015; Kollmeier et al., 2015) 등 다양한 소음하 문장인지검사 도구가 개 발되었다. 이 도구들은 모두 소프트웨어에 기반하여 신호대잡 음비(signal-to-noise ratio, SNR)를 변동하여 50\% 인지도에 해당하는 SNR을 찾으므로 고정형 소음하 어음청각검사 방법 보다 더욱 다양한 난청 정도의 대상자에게 검사가 가능하고 변 동형 검사의 특성상 소요 시간이 더 짧게 걸리는 등 임상적으 로 더 유리할 수 있다(Lee \& Yi, 2017).

국내에서 소프트웨어에 기반하여 사용 가능한 소음하 문장 인지검사 도구로는 한국어 HINT와 한국어 Matrix sentence in noise test가 있다. 한국어 HINT 검사(Moon et al., 2008)의 경우 고가의 장비를 사용해야 하고 소프트웨어상에서 하나의 제시 레벨만을 사용할 수 있고 제시 문장 수가 비교적 적은 단 점이 있으며, 현재는 한국어 HINT 검사 도구의 판매가 중지된 상황이다. 한국어 Matrix sentence in noise test의 경우 최근 한국어 Matrix 문장 음원을 녹음 및 최적화하였고(Yi, 2016), 검사의 신뢰도 및 타당도, 목록 간 동질성 등을 검증하여(Kim et al., 2017; Kim \& Lee, 2018) 현재는 소프트웨어에 기반한 변 동형 소음하 문장인지검사가 가능하다.

그러나 임상 현장에서 소음하 문장인지검사를 기본 청각검사 로 시행하는 경우는 많지 않다. 여전히 난청인을 대상으로 보청 기 착용 전 쾌적레벨(most comfortable loudness level, MCL) 에서 구한 단어인지도만으로 보청기 착용 후 의사소통능력을 예측하거나 보청기 혜택을 판단하는 경우가 있다. McRackan et al.(2016)은 MCL에서 구한 어음인지도 결과로 보청기 착용 후 의사소통능력을 유의하게 예측할 수 없음을 보고하여 기존 어음청각검사 프로토콜의 한계점을 밝혔다. 따라서 본 연구에 서는 현재 임상에서 주로 측정하는 보청기 착용 전 $\mathrm{MCL}$ 에서 구한 어음인지도로 보청기 착용 후 소음하 문장인지역치를 얼 마나 예측 혹은 설명 가능한지 확인하고자 하였다.

\section{MATERIALS AND METHODS}

\section{연구 대상}

본 연구에는 양이 대칭성 감각신경성 난청을 가진 난청인 62 명 (남 32명, 여 30명)이 참여하였다. 난청인의 평균 연령은 70.2세 [연령 범위: 34 90세, standard deviation (SD): 12.8]로 난청 외에 어지러움, 이명, 신경학적 병력을 가지고 있지 않았다. 보청 기 착용 전 3분법 $(500,1,000,2,000 \mathrm{~Hz})$ 평균순음청력역치 (pure-tone threshold average, PTA)를 구한 결과 오른쪽 귀의 $\mathrm{PTA}$ 는 평균 $54.7 \mathrm{~dB} \mathrm{HL}$ (SD: 9.6), 왼쪽 귀의 PTA는 평균
$54.5 \mathrm{~dB}$ HL (SD: 8.8)이었다. 보청기 착용 전 1,000, 2,000, $4,000 \mathrm{~Hz}$ 고주파수 평균순음청력역치(high-frequency puretone threshold average, HFPTA)를 구한 결과, 오른쪽 귀의 HFPTA는 평균 $61.4 \mathrm{~dB} \mathrm{HL}$ (SD: 9.5), 왼쪽 귀의 HFPTA는 평균 $61.1 \mathrm{~dB} \mathrm{HL}$ (SD: 9.2)이었다. 난청인 대상자 모두 양이에 보청기를 착용하고 있었으며, 각 귀에 보청기 착용 후 aided $\mathrm{PTA}$ 를 구한 결과 62명 모두 양이 간 aided PTA 차이가 $10 \mathrm{~dB}$ 이하였다. 오른쪽 귀에 보청기 착용 후 구한 PTA는 평균 35.9 $\mathrm{dB} \mathrm{HL}$ (SD: 6.1), 왼쪽 귀에 보청기 착용 후 구한 PTA는 평균 $35.2 \mathrm{~dB} \mathrm{HL}$ (SD: 6.6)이었다. Figure 1은 양쪽 귀의 보청기 착 용 전후 측정한 주파수별 순음청력역치를 보여준다. 난청 대상 자의 경우 가장 편안하다고 선호하는 보청기 적합 상태에서 연 구에 참여하였으며, 실험을 시작하기 전 성능 분석 장비(Affinity 2.0, Interacoustics, Middelfart, Denmark)를 이용하여 개개인 의 보청기 적합 상태를 확인하였다.

난청인의 소음하 문장인지도와의 비교를 목적으로 건청인 25 명(남 13명, 여 12 명)이 대조군으로 참여하였다. 건청군의 평 균 연령은 25.6세(연령 범위: 18 30세, SD: 3.9)였고, 이경을 통 한 육안 관찰 시 외이 및 고막에 이상이 없었다. 건청인의 순음 청력검사 결과 대상자 모두 $250 \mathrm{~Hz}$ 부터 $8,000 \mathrm{~Hz}$ 까지 옥타브 단위 주파수에서 $20 \mathrm{~dB} \mathrm{HL}$ 미만의 청력역치를 보였다.

\section{연구 절차}

모든 실험은 국제 표준에서 권고하는 소음허용수준(International Organization for Standardization, 2010)을 만족하는 방음실에서 실시하였다. 어음청각검사와 소음하 어음청각검사 를 시행하기 위해 청력검사기(AD629, Interacoustics), 헤드폰 (DD450, RadioEar, Middelfart, Denmark), 라우드스피커

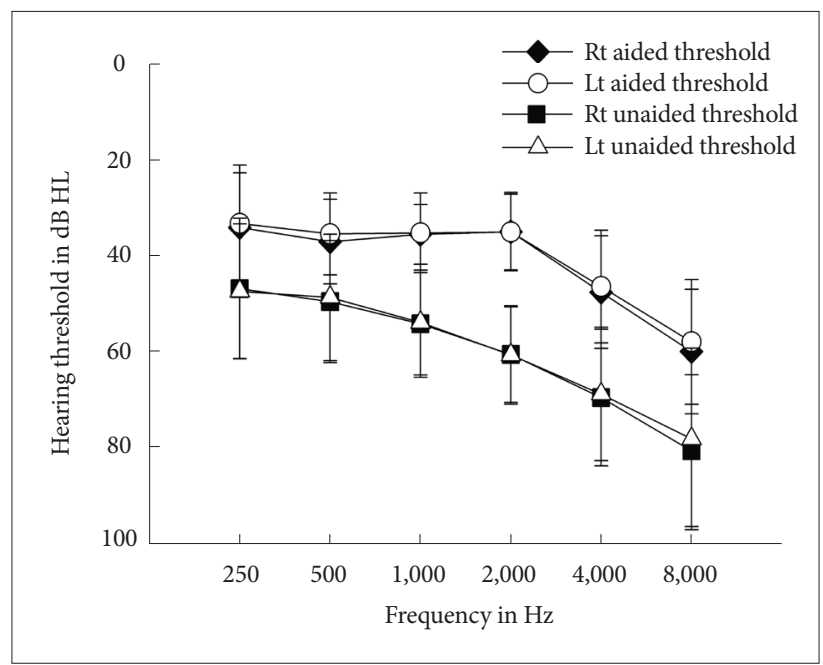

Figure 1. Mean unaided and aided hearing thresholds from 250 to $8,000 \mathrm{~Hz}$ of right and left ears. Error bar: standard deviations. 
(SP85A, RadioEar), Fireface UCX 디지털 아날로그 변환기 (RME, Haimhausen, Germany), 노트북(gram, LG electronics, Seoul, Korea)을 사용하였다.

먼저 조용한 상황에서 측정하는 어음청각검사를 시행하기 위해 헤드폰을 이용하여 각각의 귀로 듣기 편안한 MCL에서 단어나 문장을 제시하여 인지도를 구하였다. 25 개의 단어를 불 러주고 정반응한 단어를 백분율(\%)로 환산하여 WRS를 구하 였고(이하 unaided WRS), 문장 목록 내 중심단어를 기준으로 정반응한 응답을 환산(keyword scoring)하여 SRS를 계산하였 다(이하 unaided SRS).

난청인의 경우 보청기 착용 전 쾌적레벨에서 구한 어음인지도 와 보청기 착용 후 보통의 대화음레벨(normal conversational level)에서 측정한 어음인지도 간 차이가 클 수 있다(McRackan et al., 2016). 따라서 본 연구에서는 한국어의 보통대화음레벨인 $65 \mathrm{~dB}$ SPL (Han \& Lee, 2020)에서 소음 없이 어음을 제시하 고 양이 보청기 착용 후 WRS와 SRS를 측정하였다(이하 aided $\mathrm{WRS}$, aided SRS). 평가 절차상 WRS, SRS 측정을 반복하게 되므로 학습 효과를 막기 위해 서로 다른 단음절어표와 문장표 (Lee et al., 2010)를 사용하였다.

마지막으로 난청인의 양이 보청기 착용 후 소음하 문장인지 역치(aided speech recognition threshold, aided SRT)를 측정 하기 위해 라우드스피커를 통해 변동형 소음하 문장인지검사 를 시행하였다. 검사에 사용된 Matrix 문장은 문장 내 단어의 레벨을 수정(level adjustment)하여 최적화를 완료하고(Yi, 2016) 목록 검증이 이루어진 도구로(Kim \& Lee, 2018) 목록당 20개의 문장을 제시하였다. 검사에는 Matrix 문장의 스펙트럼 을 가진 비유동성 소음을 사용한다. 모든 Matrix 문장은 $10 \times$ 5 행렬(Matrix)에 포함된 50개의 단어 중 5 개의 단어를 무작위 선택 및 조합하여 문장을 구성한다(Yi, 2016). 여기서 5개의 단 어는 10 개의 주어 중 1 개, 10 개의 형용사 중 1 개, 10 개의 명사 중 1 개, 10 개의 수사 중 1 개, 10 개의 동사 중 한 개씩 임의 추출 하여 문장을 구성하므로(Appendix) $10^{5}$ 개의 서로 다른 문장 을 생성할 수 있다. 이러한 특성으로 대상자가 문장을 외우거 나 추측하여 문장 내 5 개 단어를 모두 맞추기 어렵다. 현재 Matrix 문장검사 도구는 한국어 외 15 개 이상의 다른 언어로 도 개발되었으며(미국 영어, 호주 영어, 영국 영어, 덴마크어, 네 덜란드어, 핀란드어, 프랑스어, 독일어, 이탈리아어, 노르웨이어, 폴란드어, 러시아어, 스페인어, 스웨덴어, 터키어 등) (Akeyroyd et al., 2015; Lee \& Yi, 2017), 문장의 구성, 문장 최적화 및 검 증 방법이 동일하게 적용되어 서로 다른 언어임에도 검사 결과 가 비교 가능한 장점이 있다.

본 연구에서는 난청인의 aided SRT를 측정하기 위해 Oldenburg Measurement Applications (OMA) 소프트웨어(HörTech
$\mathrm{gGmbH}$, Oldenburg, Germany)를 이용하여 $0 \mathrm{~dB}$ SNR에서 소음하 문장인지검사를 시작하였고, 소음은 $65 \mathrm{~dB} \mathrm{SPL}$ 에 고 정한 채 대상자의 반응에 따라 자동으로 문장의 레벨을 조절 하였다. 검사 시 대상자가 각 문장을 듣고 문장 내 단어를 따라 말하면 대상자의 반응에 따라 최대우도측정(maximum likelihood estimate)을 통하여 50\%의 소음하 문장인지에 해당하 는 SNR을 구하며 로지스틱 함수를 통해 speech recognition threshold (SRT)를 확인한다(Brand \& Kollmeier, 2002).

Matrix 검사의 훈련 효과를 최소화하기 위해 Akeroyd et al. (2015)의 권장 사항대로 2개의 문장 목록(40개의 문장)을 통한 연습 과정을 가진 후 실제 실험을 시작하였다.

\section{통계 분석}

수집된 결과는 Statistical Product and Service Solution 25.0(SPSS 25.0 version, IBM Corp., Armonk, NY, USA)을 이용하여 분석하였다. 기술 통계를 통해 보청기 착용 전 $\mathrm{MCL}$ 에서 측정한 unaided WRS와 unaided SRS, 보청기 착용 후 보통대화음레벨(65 dB SPL)에서 측정한 aided WRS와 aided $\mathrm{SRS}$, 소프트웨어에 기반한 변동형 검사를 통해 구한 aided SRT를 확인하였다. 대응표본 $t$ 검증을 통해 unaided WRS와 aided WRS, unaided SRS와 aided SRS가 통계적으로 유의하 게 다른지 확인하였다. 피어슨 상관분석 혹은 편상관분석을 시 행하여 여러 가지 변수와 aided SRT와의 상관성을 알아보았다. 마지막으로 단계적 다중선형 회귀분석(stepwise multiple linear regression analysis)을 통하여 여러 독립변수(unaided WRS and SRS, aided WRS and SRS, 대상자의 보청기 착용 전후 평균순음청력역치, 나이) 중 종속변수인 aided SRT를 설 명하는 데 있어 설명력이 높은 변수를 확인하였다.

\section{RESULTS}

본 연구에서는 건청군과 난청군 결과를 비교하는 것이 주 목 적이 아니었으므로 건청군과 난청군 결과를 각각 분석하여 아 래와 같이 기술하였다.

\section{건청군의 평균 어음인지도와 소음하 문장인지역치}

건청인 25명 모두 대상자의 쾌적레벨 혹은 평균 대화음 레벨 인 $65 \mathrm{~dB} \mathrm{SPL}$ 에서 헤드폰을 통해 WRS, SRS를 측정한 결과 평균 99\% 이상의 인지도를 보였다(범위: 95 100\%). 헤드폰을 통해 OMA 소프트웨어를 이용하여 변동형 Matrix 소음하 문 장인지검사를 시행한 결과, $50 \%$ 의 인지도를 보이는 SRT가 평 균 -8.91 dB SNR (SD: 0.62, range: -10.5 -8.1 dB SNR)이었 다. 건청인을 대상으로 변동형 검사가 아닌 $\mathrm{SNR}$ 을 고정하고 
Table 1. Unaided and aided speech recognition measures in 62 hearing-impaired listeners

\begin{tabular}{|c|c|c|c|c|c|c|}
\hline Condition & Presentation & Measures & Mean & Median & $\mathrm{SD}$ & Range \\
\hline \multirow[t]{10}{*}{ Quiet } & Presented at MCL & Unaided WRS & & & & \\
\hline & & Rt & $58.1 \%$ & $64.0 \%$ & 19.5 & $16.0-96.0 \%$ \\
\hline & & $\mathrm{Lt}$ & $61.9 \%$ & $64.0 \%$ & 18.6 & $16.0-96.0 \%$ \\
\hline & & Avg & $60.0 \%$ & $63.0 \%$ & 17.7 & $16.0-88.0 \%$ \\
\hline & & Unaided SRS & & & & \\
\hline & & Rt & $89.1 \%$ & $96.3 \%$ & 14.9 & $35.0-100 \%$ \\
\hline & & $\mathrm{Lt}$ & $86.7 \%$ & $92.5 \%$ & 16.8 & $25.0-100 \%$ \\
\hline & & Avg & $88.0 \%$ & $93.2 \%$ & 14.5 & $36.3-100 \%$ \\
\hline & Presented at normal conversational & Aided WRS & $67.6 \%$ & $70.0 \%$ & 16.9 & $24.0-94.0 \%$ \\
\hline & level (65 dB SPL) & Aided SRS & $91.7 \%$ & $97.5 \%$ & 12.7 & $45.0-100 \%$ \\
\hline Noise & $\begin{array}{l}\text { With adaptive procedure (noise level at } 65 \mathrm{~dB} \text { SPL, } \\
\text { speech level varied) }\end{array}$ & Aided SRT & $0.1 \mathrm{~dB}$ SNR & $-0.9 \mathrm{~dB}$ SNR & 3.9 & $-6.0-14.6 \mathrm{~dB}$ SNR \\
\hline
\end{tabular}

SD: standard deviation, MCL: most comfortable level, WRS: word recognition score, SRS: sentence recognition score, SRT: speech recognition threshold, Rt: right ear, Lt: left ear, Avg: average of both ears, SNR: signal-to-noise ratio

Matrix SRT를 측정한 결과 평균 $-9.56 \mathrm{~dB}$ SNR이었으므로(Kim $\&$ Lee, 2018) 평균 SRT 차이가 $1 \mathrm{~dB}$ 이내였다.

\section{난청군의 평균 어음인지도와 소음하 문장인지역치}

Table 1 은 양이 보청기 착용자 62 명의 보청기 착용 전후 단 어 및 문장인지도, 보청기 착용 후 소음하 문장인지역치를 보 여준다. 먼저 헤드폰을 통해 대상자의 MCL에서 각 귀의 unaided WRS와 unaided SRS를 측정하였고, 양이 보청기 착용 후 라우드스피커를 통해 $65 \mathrm{~dB}$ SPL에서 aided WRS와 aided $\mathrm{SRS}$ 를 구하였으며, 마지막으로 양이 보청기 착용 후 소프트웨 어 기반 변동형 검사 도구를 통해 소음하 문장인지역치(aided $\mathrm{SRT}$ 를 측정하였다.

Table 1에 제시하였듯이, 보청기 착용 전 MCL에서 측정한 unaided WRS의 경우 양 귀 평균 60.0\%(SD: 17.7, range: 16 88\%), unaided SRS는 평균 88.0\%(SD: 14.5, range: 36.3 100\%) 였다. 대상자 개개인의 쾌적레벨에서 단어나 문장을 제시하였 음에도 불구하고 WRS, SRS 범위 모두 상당히 넓었다. 양이 보 청기 착용 후 $65 \mathrm{~dB}$ SPL에서 구한 aided WRS는 평균 $67.6 \%$ (SD: 16.9, range: 24 94\%), aided SRS는 평균 91.7\%(SD: 12.7, range: 45 100\%)였다. 변동형 소음하 문장인지검사를 통해 aided SRT를 확인한 결과 평균 $0.1 \mathrm{~dB}$ SNR (SD: 3.9, range: $-6.0 \sim 14.6 \mathrm{~dB} \mathrm{SNR})$ 이었다. 대응 표본 $t$ 검증 결과 unaided WRS와 aided WRS, unaided SRS와 aided SRS 간 모두 유의 한 차이를 확인하였다 $(p<0.05)$.

\section{난청인의 소음하 문장인지역치와 다른 변인들 간 상관성}

피어슨 상관분석 결과 난청인의 보청기 착용 전후 측정한 평 균순음청력역치와 모든 어음청각검사 결과(unaided WRS, unaided SRS, aided WRS, aided SRS, aided SRT)가 유의한
상관성을 보였다. 즉, 난청인의 보청기 착용 전 $(\mathrm{r}=-0.44 \sim 0.38)$ 혹은 보청기 착용 후 $(\mathrm{r}=-0.52 \sim 0.35)$ 청력이 좋을수록 조용한 상황 혹은 소음 상황에서 측정한 어음인지 결과가 유의하게 좋 았다 $(p<0.05)$. 난청인의 연령이 많을수록 소음하 문장인지 능력이 유의하게 나빴고 $(\mathrm{r}=0.37, p<0.05)$ 나머지 조용한 환 경에서 측정한 인지 결과와는 유의한 상관성이 없었다.

위에서 난청인 대상자의 청력과 연령이 소음하 문장인지에 영향을 미칠 수 있는 변수임을 확인하였으므로 보청기 착용 전 후의 평균순음청력역치, 대상자의 연령을 각각 통제한 상태에 서 편상관분석을 추가로 시행하였다. 분석 결과 두 변수를 통 제변수로 사용한 경우 조용한 상황에서 측정한 모든 인지도 결 과가 소음하 문장인지역치와 유의한 상관성을 보이지 않았다 $(p>0.05)$.

\section{난청인의 소음하 문장인지역치 예측 변인 분석}

국내의 경우 임상 현장에서 보청기 착용 전 대상자의 $\mathrm{MCL}$ 에서 측정한 단어인지도만으로 보청기 착용 후 소음하 의사소 통능력을 어느 정도 예측할 수 있을 거라 가정하고 보청기 착 용 후 소음하 어음청각검사를 추가로 시행하지 않는 경우가 많 다. 그러나 이러한 가정은 설득력이 없으며 반드시 보청기 착용 후 추가로 음장 어음청각검사를 시행해야 한다고 보고한 바 있 다(McRackan et al., 2016). 따라서 단계적 다중선형 회귀분석 을 통해 MCL에서 구한 unaided WRS나 SRS, aided WRS나 $\mathrm{SRS}$, 대상자의 평균순음청력역치, 나이 중 소음하 문장인지역 치를 설명하는 데 가장 설명력이 높은 변수를 확인하였다.

분석 결과(Table 2) 위에서 열거한 여러 변수 중 설명력이 가 장 높은 변수는 보청기 착용 후 측정한 aided SRS였다. Unaided WRS나 unaided SRS는 소음하 문장인지역치를 유의하게 설 명할 수 있는 변수가 아니었으며, 보통대화음레벨에서 측정한 
Table 2. Predictors of aided speech recognition threshold obtained from Korean Matrix sentence-in-noise test

\begin{tabular}{lcc}
\hline \multicolumn{1}{c}{ Predictors } & $\begin{array}{c}\text { Standardized } \beta \\
\text { coefficient }^{\dagger}\end{array}$ & Adjusted $\mathrm{R}^{2}$ \\
\hline Aided SRS (at 65 dB SPL) & $-0.589^{*}$ & 0.384 \\
Age & $0.290^{*}$ & 0.459 \\
\hline
\end{tabular}

${ }^{*} p<0.05,{ }^{\dagger} 95 \%$ confidence intervals. SRS: sentence recognition score

aided SRS가 소음하 문장인지역치(aided SRT)를 약 38.4\%가 량 설명할 수 있었고, 대상자의 나이가 추가로 포함되었을 경우 약 $7 \%$ 가량의 설명력이 증가하였다. 이러한 결과는 보청기 착용 전 MCL에서 구한 어음인지도만으로 보청기 착용 후 소음 상 황에서의 의사소통능력을 유의하게 예측 혹은 설명할 수 없음 을 의미한다.

\section{DISCUSSIONS}

난청인에게 적절한 보청기를 선택하기 위해 보청기 착용 전 후 다양한 청각검사를 시행하게 된다. 보청기 착용 전 대상자의 $\mathrm{MCL}$ 에서 WRS 혹은 SRS를 측정하는 이유는 추후 보청기로 소리를 편안하게 들을 수 있도록 잘 적합되었을 때 얼마나 어 음을 정확하게 인지할 수 있을 것인지 예측하기 위함이다. 그러 나 보청기를 착용한 이후부터는 실제로 음장 어음청각검사를 시행하여 조용한 상황 혹은 소음 상황에서 보청기 착용으로 인해 어음인지가 얼마나 개선되는지 알아보아야 한다. 소음이 있는 일상생활 속 의사소통능력을 보다 빠르고 신뢰도 있게 정 량화하기 위해 소프트웨어 기반 소음하 문장인지도를 평가하 는 것이 좋다(Theunissen et al., 2009). 그러나 국내 임상 현장 에서는 소요 시간, 적절한 음장검사 환경 부족, 음장검사 도구 의 부족 등의 이유로 인해 조용한 상황 혹은 소음 상황에서 음 장 어음청각검사를 생략하는 경우가 많다. 따라서 본 연구에서 는 난청인의 경우 소음하 문장인지역치가 어떠한지, 임상 현장 에서 주로 시행하는 기존 어음청각검사 결과(보청기 착용 전) 가 보청기 착용 후 소음하 문장인지역치를 어느 정도 예측 혹 은 설명 가능한지 확인하고자 하였다.

분석 결과 건청인은 약 $-9 \mathrm{~dB} \mathrm{SNR}$ 의 듣기 조건에서도 문장 을 $50 \%$ 가량 인지할 수 있었다. 즉, 건청인은 일상생활에서 목 표 문장의 강도가 소음의 강도보다 $9 \mathrm{~dB}$ 가량 더 작은 조건에 서도 문장을 이해할 수 있음을 의미한다. 그러나 난청인의 경 우 건청인과는 다른 결과를 보였다. 첫 번째로, 난청인 대상자 가 듣기 편안한 MCL에서 어음을 제시하였음에도 불구하고 평 균 $63 \%$ 의 단어인지도를 보였으며, 대상자 간 단어 및 문장 인 지도 차이가 큰 편이었다(WRS 범위: $16 ~ 88 \%$, SRS 범위: 약 36 100\%). 두 번째, 양이 보청기 착용 후 평균 대화음 레벨(65 dB
$\mathrm{SPL}$ )에서 구한 어음인지도 역시 개인 간 차이가 컸으며(WRS 범위: 24 94\%, SRS 범위: 약 45 100\%), MCL에서 측정한 unaided WRS와 SRS가 $65 \mathrm{~dB}$ SPL에서 구한 aided WRS 및 $\mathrm{SRS}$ 와 유의하게 달랐다. 마지막으로 소프트웨어에 기반한 변 동형 검사 절차로 난청인의 Matrix SRT를 측정한 결과 평균 $0.1 \mathrm{~dB}$ SNR (범위: -6 14.6 dB SNR)의 결과를 보였다. 건청인 의 평균 SRT가 약 $-9 \mathrm{~dB}$ SNR이었음을 고려하면 난청인은 건 청인에 비해 소음 대비 문장의 강도가 약 9 $10 \mathrm{~dB}$ 은 커야 유 사한 인지도를 보일 수 있음을 의미한다.

Wardenga et al.(2015)은 다양한 난청 정도를 보이는 난청인 을 대상으로 독일어 Matrix SRT를 측정한 결과 중도, 중고도 난청인의 경우 약 $-5 \sim 2 \mathrm{~dB}$ SNR의 Matrix SRT를 보임을 보고 하였다. Hey et al.(2014)은 38명의 인공와우 착용인을 대상으 로 독일어 Matrix 소음하 문장인지역치를 측정한 결과 평균 -2 $\mathrm{dB}$ SNR가량의 SRT를 보였다. 이 연구에서는 소음 없이 $65 \mathrm{~dB}$ 의 보통대화음레벨의 문장을 $75 \%$ 이상 인지하는 인공와우 이 식 대상자만을 대상으로 하였으므로 본 연구의 결과보다 문장 인지능력이 더 좋았을 것이다. Hey et al.(2014)은 인공와우 대 상자에게 소프트웨어 기반 Matrix 검사를 시행한 경우 고정된 $\mathrm{SNR}$ 을 이용한 검사보다 소요 시간이 더 짧게 걸렸으므로 이 검 사 도구를 난청인을 위한 임상에서 사용할 것을 권장하였다.

본 연구의 상관분석 결과에서 난청인의 청력이나 나이를 통 제하고 편상관분석을 시행하였을 때 조용한 상황에서 측정하 는 기존의 어음청각검사 결과와 소음하 문장인지역치 간 유의 한 관련성이 없었다. 단계적 다중선형 회귀분석 결과에서도 unaided WRS, unaided SRS는 보청기 착용 후 측정한 소음하 문장인지역치를 예측하는 변인이 아니었다. 즉, 상관분석과 회 귀분석 결과 모두 현재 기초청각검사로 MCL에서 측정하는 WRS 혹은 SRS로는 보청기 착용 후 소음하 의사소통능력을 예측하는 데 한계가 있음을 의미한다. 이러한 결과는 국내보다 는 국외의 연구에서 다수 검증된 바 있다. 예를 들어 94 명의 보 청기 착용자의 어음청각검사 결과를 비교한 McRackan et al. (2016)은 MCL에서 구한 unaided WRS로 실제 보청기 착용 후 어음인지도를 유추하는 것은 설득력이 없다고 하였다. Killion \& Gudmundsen(2005) 또한 보청기 착용 전 측정한 어음청각검사 결과로 보청기 착용 후 주관적 보청기 만족도나 의사소통능력 의 개선 정도를 예측할 수 없다고 하였다. Wilson(2011) 역시 중도 고도 난청인의 데이터를 분석한 결과 대상자 중 $50 \%$ 가 $90 \%$ 이상의 NU6 단어인지도를, 대상자 중 $70 \%$ 가 $80 \%$ 이상 의 NU6 단어인지도를 보였으나, 대상자 중 $10 \%$ 이하만이 정상 범위의 소음하 word-in-noise (WIN) 어음인지도를 가졌다고 하였다.

본 연구의 결과와 위의 국외 선행연구 결과를 종합하면 다음 
과 같이 정리할 수 있다. 보청기 착용 전 MCL에서 구하는 단 어인지도 혹은 문장인지도는 난청의 진단 및 보청기를 선택할 때 중요하게 고려되어야 하는 결과 중 하나이다. 그러나 $\mathrm{MCL}$ 에서 구한 어음인지도를 통해 보청기 착용 후 소음하 어음인지 도를 예측하거나 보청기 혜택의 정도를 판단하는 것은 적절한 방법이 아니다. 소음 상황에서 의사소통능력 혹은 보청기 혜택 을 측정하기 위한 목적이라면 반드시 보청기 착용 전후 소음하 어음청각검사를 시행하고 비교하여 이를 신뢰도 있게 정량화 해야 한다.

\section{중심 단어 : 매트릭스 문장인지검사·소프트웨어 기반 소음하} 문장인지·소음하 어음인지능력.

\section{Ethical Statement}

All procedures were approved by the Institutional Review Board of Hallym University of Graduate Studies (IRB: \#HUGSAUD361879).

\section{Acknowledgments}

N/A.

\section{Declaration of Conflicting Interests}

There are no conflict of interests.

\section{Funding}

This work was supported by the Ministry of Education of the Republic of Korea and National Research Foundation of Korea (NRF-2016S1A5A 8020353).

\section{Author Contributions}

G.K. performed experiments, analyzed data, and created tables and figures; G.K. and J.L. designed experiments and wrote the paper. Also, all authors discussed the results together and implications and commented on the manuscript at each stage.

\section{ORCID iDs}

Gwang Min Kim

Jae Hee Lee

https://orcid.org/0000-0003-3223-8016

https://orcid.org/0000-0002-4152-6434

\section{REFERENCES}

Akeroyd, M. A., Arlinger, S., Bentler, R. A., Boothroyd, A., Dillier, N., Dreschler, W. A., et al. (2015). International Collegium of Rehabilitative Audiology (ICRA) recommendations for the construction of multilingual speech tests. ICRA Working Group on multilingual speech tests. International Journal of Audiology, 54 Suppl 2, 17-22.

Brand, T. \& Kollmeier, B. (2002). Efficient adaptive procedures for threshold and concurrent slope estimates for psychophysics and speech intelligibility tests. The Journal of the Acoustical Society of America, 111(6), 28012810.

Byun, S. W., Chung, S. M., Kim, H. S., \& Go, Y. M. (2005). A survey of phonetically balanced words lists used in training hospitals in Korea. Korean Journal of Otorhinolaryngology-Head and Neck Surgery, 48(9), 1086-1090

Han, Y. K. \& Lee, K. (2020). A study on the Korean conversation speech level and spectrum in sound-treated environment. Audiology and Speech Research, 16(2), 133-139.

Hey, M., Hocke, T., Hedderich, J., \& Müller-Deile, J. (2014). Investigation of a matrix sentence test in noise: Reproducibility and discrimination function in cochlear implant patients. International Journal of Audiology, 53(12), 895-902.

International Organization for Standardization. (2010). ISO 8253-1:2010. Acoustics-Audiometric Test Methods-Part 1: Pure-Tone Air and Bone Conduction Audiometry. Geneva: ISO.

Killion, M. C. \& Gudmundsen, G. I. (2005). Fitting hearing aids using clinical prefitting speech measures: An evidence-based review. Journal of the American Academy of Audiology, 16(7), 439-447.

Killion, M. C., Niquette, P. A., Gudmundsen, G. I., Revit, L. J., \& Banerjee, S. (2004). Development of a quick speech-in-noise test for measuring signal-to-noise ratio loss in normal-hearing and hearing-impaired listeners. The Journal of the Acoustical Society of America, 116(4 Pt 1), 23952405.

Kim, K. H. \& Lee, J. H. (2018). Evaluation of the Korean matrix sentence test: Verification of the list equivalence and the effect of word position. Audiology and Speech Research, 14(2), 100-107.

Kim, N. K., Yi, D., Bahng, J., \& Lee, J. H. (2017). Study on the reliability and the validity for the sentence-in-noise scores at the fixed signal-tonoise ratios. Audiology and Speech Research, 13(1), 62-69.

Kollmeier, B., Warzybok, A., Hochmuth, S., Zokoll, M. A., Uslar, V., Brand, T., et al. (2015). The multilingual matrix test: Principles, applications, and comparison across languages: A review. International Journal of Audiology, 54 Suppl 2, 3-16.

Lee, J. H., Cho, S. J., Kim, J. S., Jang, H. S., Lim, D. H., Lee, K. W., et al. (2010). Korean Speech Audiometry (KSA). Seoul: Hakjisa.

Lee, J. H. \& Yi, D. W. (2017). A comparison of adaptive sentence-in-noise tests. Audiology and Speech Research, 13(1), 9-18.

McCormack, A. \& Fortnum, H. (2013). Why do people fitted with hearing aids not wear them? International Journal of Audiology, 52(5), 360-368.

McRackan, T. R., Ahlstrom, J. B., Clinkscales, W. B., Meyer, T. A., \& Dubno, J. R. (2016). Clinical implications of word recognition differences in earphone and aided conditions. Otology and Neurotology, 37(10), 14751481.

Mendel, L. L. (2008). Current considerations in pediatric speech audiometry. International Journal of Audiology, 47(9), 546-553.

Mendel, L. L. \& Danhauer, J. L. (1997). Audiologic Evaluation and Management and Speech Perception Assessment. San Diego, CA: Singular Publishing.

Moon, S. K., Kim, S. H., Mun, H. A., Jung, H. K., Lee, J. H., Choung, Y. H., et al. (2008). The Korean hearing in noise test. International Journal of Audiology, 47(6), 375-376.

Nilsson, M., Soli, S. D., \& Sullivan, J. A. (1994). Development of the hearing in noise test for the measurement of speech reception thresholds in quiet and in noise. The Journal of the Acoustical Society of America, 95(2), 1085-1099.

Taylor, B. (2003). Speech-in-noise tests: How and why to include them in your basic test battery. The Hearing Journal, 56(1), 40, 42-46.

Theunissen, M., Swanepoel, de W., \& Hanekom, J. (2009). Sentence recognition in noise: Variables in compilation and interpretation of tests. International Journal of Audiology, 48(11), 743-757.

Wardenga, N., Batsoulis, C., Wagener, K. C., Brand, T., Lenarz, T., \& Maier, H. (2015). Do you hear the noise? The German matrix sentence test with a fixed noise level in subjects with normal hearing and hearing impairment. International Journal of Audiology, 54 Suppl 2, 71-79.

Wilson, R. H. (2011). Clinical experience with the words-in-noise test on 3430 veterans: Comparisons with pure-tone thresholds and word recognition in quiet. Journal of the American Academy of Audiology, 22(7), 405-423.

Yi, D. (2016). Study on the construction and optimization of the Korean matrix sentence materials (Unpublished master's thesis). Hallym University of Graduate Studies, Seoul. 
APPENDIX $\square$

한국어 매트릭스 문장조합에 사용되는 단어 예시

\begin{tabular}{|l|l|l|l|l|}
\hline Name & Adjective & Noun & Numeral & Verb \\
\hline 건우는 & 새로운 & 책상 & 한 개를 & 본다 \\
\hline 철수는 & 작은 & 의자 & 두 개를 & 받았다 \\
\hline 준호는 & 파란 & 주사위 & 세 개를 & 판다 \\
\hline 은서가 & 커다란 & 장난감 & 네 개를 & 좋아한다 \\
\hline 슬기가 & 가벼운 & 숟가락 & 다섯 개를 & 빌렸다 \\
\hline 민준이는 & 예쁜 & 반지 & 여섯 개를 & 만든다 \\
\hline 동준이는 & 깨끗한 & 접시 & 일곱 개를 & 주웠다 \\
\hline 유진이가 & 멋진 & 바구니 & 여덟 개를 & 산다 \\
\hline 서영이가 & 빨간 & 연필 & 아홉 개를 & 발견했다 \\
\hline 지민이가 & 하얀 & 풍선 & 열 개를 & 주문했다 \\
\hline
\end{tabular}

